\section{A OPINIÃO DE ATLETAS E TREINADORES DE VOLEIBOL SOBRE A PARTICIPAÇÃO DE MULHERES TRANS}

\author{
VOLLEYBALL ATHLETES'AND COACHES' VIEWS ON PARTICIPATION \\ OF TRANSGENDER WOMEN C
}

\section{LA OPINIÓN DE ATLETAS Y ENTRENADORES DE VOLEIBOL SOBRE LA PARTICIPACIÓN DE MUJERES TRANS C}

doi) https://doi.org/10.22456/1982-8918.101993

Rafael Marques Garcia* <rafa.mgarcia@hotmail.com>

Erik Giuseppe Barbosa Pereira* <egiuseppe@eefd.ufrj.br>

*Universidade Federal do Rio de Janeiro. Rio de Janeiro, RJ, Brasil.
Resumo: Objetivamos averiguar a opinião de atletas e treinadores de voleibol sobre a participação de mulheres trans no voleibol feminino a partir do caso da atleta Tifanny Abreu. Para nortear esse objetivo, indagamos: qual o posicionamento dos(as) envolvidos(as) acerca dessa atuação e como estruturam e apresentam seu ponto de vista? Coletamos 38 reportagens do site esportivo globoesporte.com que tratavam sobre a participação trans no voleibol a partir do caso de Tifanny. Desse total, apenas 11 coberturas traziam o depoimento de 9 atletas e 4 treinadores, que foram analisados pela técnica de análise de discurso. Como resultados, percebemos que o grupo estudado foi, em maioria, contrário a essa inserção e atuação com base em normas biomédicas e fisiológicas cis-heteronormativas. Entretanto, registraramse manifestações mais cautelosas sobre o assunto, legitimando a participação de acordo com as recomendações das confederações e federações que regem as modalidades esportivas.

Palavras chave: Esportes. Voleibol. Pessoas transgênero.
Recebido em: $14-04-2020$ Aprovado em: 29-06-2020 Publicado em: 30-09-2020

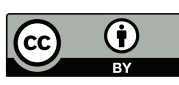

Este é um artigo publicado sob a licença Creative Commons Atribuição 4.0 Internacional (CC BY 4.0).

eISSN: 1982-8918 


\section{INTRODUÇÃO}

As normas de gênero estão presentes em inúmeras - senão todas - as comarcas sociais que validam e permitem a existência de corpos nos planos físico, simbólico e social. Vergueiro $(2014 ; 2015)$ sugere, a partir das teorias decoloniais e póscoloniais ${ }^{1}$, que nossa sociedade é estruturada por um sistema de mundo (re)produtor de hierarquias epistêmicas entre grupos e sujeitos a partir de um reconhecimento desigual dos marcadores sociais, tais como gênero, sexualidade, raça/etnia, classe social, religião, geração, espectro político, entre outros. A esse regime que dita as relações sociais em termos organizacionais, civilizatórios e relacionais seguindo o ponto de vista do colonizador, é dado o nome de cistema-mundo².

Dentro do cistema-mundo, as categorias de gênero e sexualidade são construídas levando em consideração a ideia coerente entre sexo de nascimento, gênero social e orientação afetivo-sexual que, em suma, traduz-se no regime conhecido como cisheteronormatividade. Este regimento, como explicam Jardim (2018) e Couto Junior et al. (2019) é um regulamento político de vida que institui normas policiadoras de gênero e de orientação sexual sobre os corpos com o intuito de assegurar a heterossexualidade reprodutora e, assim, desqualificar os/as desviantes das práticas heterossexuais, isto é, os/as que não se identificam nesta orientação e/ou produzem masculinidades e feminilidades em descompasso com o gênero designado em seu nascimento.

A partir disto, podemos entender os desdobramentos do cistema sexual e de gênero sobre os sujeitos. A pessoa cissexual é aquela que se reconhece no sexo que Ihe foi atribuído biologicamente. Ao desempenhar os papéis de gênero atribuídos ao seu sexo, a pessoa adota, então, a identidade cisgênero. Em linhas gerais, resumir uma pessoa à identidade cis significa dizer que ela se reconhece no sexo e gênero que lhe foram atribuídas ao nascimento (VERGUEIRO, 2014; 2015).

Já para aquelas pessoas que não se reconhecem abarcadas por essa cistematização obrigatória entre o sexo e o gênero, é-lhes atribuído a nomenclatura trans que, nos dizeres de Jesus (2012), traduz-se como ir além de, podendo fixar sua identidade nos papéis sexuais e sociais do sexo/gênero oposto aos atribuídos no nascimento, ou ainda não estabelecer qualquer sentimento de pertença fixa a uma identificação, sendo, portanto, fluida. À primeira manifestação, dá-se o nome de transexualidade e, à segunda, transgeneridade.

Neste sentido, é possível compreender como o cistema-mundo privilegia as pessoas cis, ou melhor, como as pessoas que se enquadram dentro do cistema

\footnotetext{
1 Vergueiro $(2014 ; 2015)$ elucida que a decolonialidade é uma linha epistemológica emergente na América Latina que almeja problematizar a modernidade a partir dos estudos étnicos, questionando as matrizes coloniais de poder. Já o pós-colonialismo concentra-se em analisar os legados sociopolíticos e culturais deixados pelo processo de colonização tanto nos países colonizados quanto nos colonizadores.

2 Vergueiro (2015, p. 15), em alusão ao trabalho "Descolonizar as esquerdas ocidentalizadas: para além das esquerdas eurocêntrica rumo a uma esquerda transmoderna descolonial" (2012), do sociólogo porto-riquenho Ramón Grosfoguel, situa-nos quanto a estruturação do cistema-mundo. Neste, a genealogia da cisgeneridade e seus correlatos são construídos, caracterizando-o como "[...] "[c]istemamundo ocidentalizado/cristianocêntrico moderno/ colonial capitalista/patriarcal" que produz "hierarquias epistêmicas" em que [...] perspectivas não cisgêneras são excluídas, minimizadas, ou silenciadas. A corruptela 'cistema', entre outras corruptelas do tipo, têm o objetivo de enfatizar o caráter estrutural e institucional - 'cistêmico' - de perspectivas cis+sexistas, para além do paradigma individualizante do conceito de 'transfobia'".
} 
possuem diminuição da precarização e vulnerabilidade da condição de vida sistêmica, sendo, portanto, melhores reconhecidas e tendo suas práticas sociais mais valoradas e permitidas.

As pessoas trans não encontram guarida, tampouco respaldo, para se inserirem e permanecerem nas práticas esportivas cistêmicas, a não ser que renunciem sua identificação pessoal subordinada ao cistema esportivo, adotando e fixando compulsoriamente uma identidade cissocial, isto é, que Ihe garanta a passabilidade de gênero cis.

A passabilidade, implicada em uma performatividade de gênero, dispõe um conjunto de atos regulados e repetidos que asseguram uma imagem substancial de gênero no registro de uma matriz heterossexual e cisgênera [...] Indicam-se, assim, práticas cotidianas implicadas na produção e manutenção de uma determinada corporalidade, um policiamento constante das fronteiras (PONTES; SILVA, 2018, p. 407).

É seguindo essa linha de raciocínio que o Esporte emerge como mais um espaço das performatividades de gênero, servindo como locus binário de experimentação corporal e político, demarcando as hierarquias sociais de gênero e reforçando as desigualdades entre o masculino e o feminino (GRESPAN; GOELLNER, 2014).

Com foco maior nas identificações trans no Esporte, as pesquisas internacionais ganham notoriedade após a publicação do Comitê Olímpico Internacional (COI) sobre as novas recomendações de competição para transgêneros e intersexuais, no final de 2015 (MACHADO, 2019). No Brasil, esses estudos se caracterizam a partir de dois prismas: 1- concentram-se na esfera da Biomedicina, não atingindo as Ciências do Esporte, o que suscita inúmeras dúvidas e questionamentos sobre a legalidade desta participação; e 2- na Educação Física, os trabalhos que problematizam as manifestações dissonantes das cisheteronormativas no Esporte encontram-se em ascensão desde meados da década de 2010, através de autores como Wagner Camargo, Silvana Goellner, Luiza dos Anjos, Leandro Brito, Bárbara Pires, Thiago Iwamoto, Ludmila Mourão, Vagner Prado e Erik Pereira.

Esse assunto tem ganhado atenção em decorrência da participação da atleta trans de voleibol Tifanny Abreu, que atua pela equipe feminina no SESI/Vôlei Bauru, do interior paulista, desde dezembro de 2017. Tifanny foi a primeira mulher trans a competir no alto rendimento esportivo brasileiro, atraindo a atenção de inúmeros veículos midiáticos, de estudiosos e de debatedores do tema.

Face ao exposto, o objetivo deste trabalho é averiguar a opinião de atletas e treinadores de voleibol sobre a participação de mulheres trans no voleibol feminino a partir do caso de Tifanny Abreu. Para nortear esse objetivo, indagamos: qual o posicionamento dos/as envolvidos/as acerca dessa participação e como estruturam e apresentam seu ponto de vista?

A presente pesquisa se justifica pela relevância de registrar os interesses de atletas e treinadores diretamente envolvidos/as na competição, possibilitando trazer aqui a livre expressão e o diálogo para com todas as partes. Cientes da sensibilidade e polêmica do tema, prezamos pela livre e democrática exposição de argumentos e ideias, com serenidade e reconhecimento das diversidades e diferenças que permeiam, sobretudo (re)estruturam, o cistema esportivo atual. 


\section{ASPECTOS METODOLÓGICOS}

Este estudo, de natureza qualitativa, optou por analisar como os treinadores e as atletas cis de voleibol de alto rendimento se posicionavam com relação à participação de atletas mulheres trans. A seleção do material empírico concentrouse em fontes de informação disponíveis online, haja vista que as fontes jornalísticas têm grande alcance (inter)nacionalmente e são de domínio público. Para apurar qual delas investigar, seguimos os seguintes critérios de delimitação:

1. Escolha do portal de coleta de acordo com o ranking dos sites mais visitados no Brasil, disponibilizado pela SimilarWeb ${ }^{3}$ em março de $2020^{4}$. Nesta etapa, verificamos que a Globo.com, que reúne todo o conteúdo jornalístico, esportivo e de entretenimento da Rede Globo, a emissora de maior audiência do país, figurava em $4^{\circ}$ lugar e, dentre as plataformas de notícias, era a primeira delas, ou seja, a de maior alcance de público. Desta forma, direcionamo-nos à seção esportiva da rede, sendo o site globoesporte.com;

2. Busca na plataforma por reportagens em que os/as sujeitos/as da pesquisa tratavam do assunto, no período compreendido entre dezembro de 2017 (quando Tifanny estreou na competição nacional) e março de 2020 (quando confeccionamos a presente pesquisa).

Após essa fase, identificamos um total de 38 reportagens que tratavam sobre a participação trans no voleibol a partir do caso de Tifanny. Deste total, descartamos 27 coberturas por serem apenas explicativas e não conterem depoimentos de atletas e/ou treinadores, ficando assim com apenas 11 matérias. Estas traziam à tona o depoimento de 9 atletas e 4 treinadores. De posse desse material, recortamos os depoimentos de nossos sujeitos-alvo para que pudessem ser analisados através da técnica de análise de discurso (GILL, 2002; ORLANDI, 2011).

Desta forma, compreendemos que o discurso se constitui em ordem de sentido entre interlocutores, pincelando um quadro social geral que traduz uma situação, um contexto sócio-histórico e significativo-simbólico à sequência discursiva que foi proferida (ORLANDI, 2011). Neste sentido, para que seja possível analisá-lo, adotamos as etapas propostas pela autora, que orienta esse processo em quatro fases: a primeira refere-se à descrição literal do discurso; a segunda é denominada de redução fenomenológica, onde separam-se os trechos mais significativos e pertinentes de acordo com o objeto de estudo; a terceira é uma ordenação desse material para que possa ser trabalhado e; por fim, a interpretação do fenômeno, onde são realizadas problematizações acerca do conteúdo levantado.

\section{RESULTADOS E DISCUSSÃO}

Nas 11 reportagens selecionadas, identificamos o depoimento de 9 atletas, sendo 2 delas já aposentadas e de 4 técnicos em atuação (no momento de concessão das entrevistas). Para facilitar a leitura dos posicionamentos, organizamos nossos

\footnotetext{
3 Companhia de tecnologias que fornece serviços em web analytics, data mining e inteligência empresarial para corporações internacionais. Usa tecnologias big data para colecionar, medir, analisar e providenciar estatísticas de envolvimento de utilizadores para websites e aplicações móveis.

4 SIMILARWEB, 2020. Disponível em: https://www.similarweb.com/pt/top-websites/brazil. Acesso em: 06 ago. 2020.
} 
resultados em dois grandes blocos, sendo o primeiro destinado à fala das atletas e o segundo à fala dos treinadores. Um terceiro bloco foi sinalizado para discutir de forma coesa os discursos do grupo amostral.

\subsection{O DISCURSO DAS ATLETAS}

Ana Paula Henkel: Muitas jogadoras não vão se pronunciar com medo da injusta patrulha, mas a maioria não acha justo uma trans jogar com as mulheres. E não é. Corpo foi construído com testosterona durante a vida toda. Não é preconceito, é fisiologia. Por que não então uma seleção feminina só com trans? Imbatível! ${ }^{5}$

Ana Paula é ex-atleta, brasileira e reside nos Estados Unidos. Já defendeu a seleção nacional e possui uma carreira vitoriosa, sendo amplamente reconhecida por suas conquistas nas quadras, em especial a medalha de bronze nos Jogos Olímpicos de Atlanta, em 1996. Atualmente, vem ganhando destaque nas mídias sociais por posicionar seu espectro político conservador e também por travar uma batalha incansável a favor dos direitos das mulheres cis no Esporte, sendo contrária às recomendações do $\mathrm{COI}$ de 2015 que flexibilizam a participação de atletas trans e intersexuais em competições pelo mundo. Sustenta sua posição contrária sob o argumento de que estudos longitudinais e com um público maior precisam ser realizados para averiguar mais profundamente os impactos da terapia hormonal no rendimento do corpo trans. Em carta aberta veiculada ao COI no ano de 2018, nomeou a decisão da entidade de "apressada e irrefletida".

Virna Dias: Gente, quem tem que resolver isso [convocação para a Seleção] é o Zé Roberto. Quem somos nós para julgá-la? Se ela é uma atleta aprovada para jogar como mulher no cenário feminino, eu não vejo problema dela ser convocada. Agora, quem decide e vai analisar (convocação) é o Zé Roberto [...] Não sei como isso é visto internacionalmente, mas vamos ficar na torcida porque vai ser uma força extraordinária. ${ }^{6}$

Virna é ex-atleta, brasileira e também já defendeu a seleção, sendo um ícone da modalidade, (inter)nacionalmente reconhecida principalmente pela conquista dos bronzes olímpicos nos Jogos de Atlanta (1996) e Sidney (2000). Para Virna, a convocação de Tifanny depende única e exclusivamente da decisão do técnico José Roberto e acredita que, se ocorrer, será um reforço de grande valia para o Brasil. Também, diz que o momento do voleibol brasileiro é de transição, fator que poderia auxiliar no chamamento de Tifanny.

Thaísa Daher de Menezes: Não cabe a mim falar, se acho que deve ou não deve. Não tenho que achar nada, não sou eu que defino nada, não estudei para isso e não estou ali para julgar e dizer se pode ou não pode... isso fica para os órgãos competentes. Tem que ver o lado humano da Tifanny, ela é uma jogadora como eu e tenho de dar força para ela. Tem que correr atrás dos seus sonhos e se amanhã as pessoas que decidem falarem que não pode mais jogar, vou apoiar da mesma forma. Estou aqui para jogar vôlei, não para discutir se pode ou não pode. Preciso dar o meu melhor para tentar parar e defender ela nos jogos. Ela é tão forte quanto a Tandara. As duas têm grande pontuação alta porque recebem $80 \%$ das bolas do time.

5 ANA PAULA critica... Disponível em: https://globoesporte.globo.com/volei/noticia/ana-paula-critica-liberacao-detrans-na-superliga-nao-e-preconceito-e-fisiologia.ghtml. Acesso em: 06 ago. 2020.

6 MARTINS, Josiel. Virna apoia Tifanny na seleção feminina de vôlei: "Quem somos nós para julgar?” Disponível em: https://globoesporte.globo.com/pi/noticia/virna-apoia-tiffany-na-selecao-feminina-de-volei-quem-somos-nos-parajulgar.ghtml. Acesso em: 08 ago. 2020. 
Não podemos focar apenas no número de pontos que elas fazem, mas também no número de bolas que recebem. Sou amiga dela, conversamos muito e temos uma amizade absurda. A Tifanny é uma pessoa muito doce, que quero muito o bem e que esteja do meu lado. Sempre darei força para que ela seja feliz, porque merece muito. ${ }^{7}$

Thaísa Daher é uma atacante de meio de rede, bicampeã olímpica pelo Brasil nos Jogos de Pequim (2008) e Londres (2012), defendendo atualmente a equipe do Itambé/Minas Tênis Clube. Já concedeu entrevistas dizendo que apoia o caso de Tifanny, ressaltando que não cabe às atletas, torcedores/as e comissão técnica decidirem sobre a participação de mulheres trans no esporte feminino, mas sim aos órgãos competentes que regulamentam as competições esportivas, tais como o COI e, mais especificamente no caso do voleibol, a Federação Internacional de Voleibol (FIVB) e a Confederação Brasileira de Voleibol (CBV).

Fabiana Alvim de Oliveira: Para mim, não achei nada de anormal. $\mathrm{Na}$ minha visão ela faz diferença para o time delas, como a Gabi faz para a gente. É uma jogadora que tem a força do nível da Tandara, de jogadoras mundiais. Em muitos momentos conseguimos neutralizá-la. Não vejo problema nenhum [na presença dela]. Bauru vem crescendo no segundo turno, tem feito grandes partidas. Marília acolheu o time, a torcida compareceu. Os times alternaram bons momentos, fomos mais constantes no saque. A Tifanny jogou bem, é uma referência para a Juma e soubemos neutralizar bem e defender. Fizemos um bom jogo diante de um adversário que está crescendo. ${ }^{8}$

Fabiana de Oliveira, mais conhecida como Fabi, é ex-líbero da seleção, também bicampeã olímpica nos Jogos de Pequim (2008) e Londres (2012), tendo defendido a equipe do Unilever Vôlei (hoje SESC/Flamengo) por toda a carreira. Fabi minimiza a polêmica sobre o caso Tifanny alegado que o desempenho da atleta é mais um dentre as componentes de um time, já tendo enfatizado também que se os órgãos regulamentares a autorizaram a participar, não há motivos que impeçam essa atuação.

Tandara Alves Caixeta: Eu respeito a história dela, para a sociedade é muito importante, dar a cara para bater, é uma pessoa que eu respeito muito. É um assunto delicado. Eu estava segurando para falar sobre isso porque estava esperando nosso confronto. Estudei, falei com muita gente sobre o assunto, tive um respaldo e eu não concordo com ela jogar no vôlei feminino. A puberdade dela inteira se desenvolveu como sexo masculino. Não é preconceito, é fisiologia. Precisamos saber diferenciar isso. O pulmão dela é maior, o coração dela é maior, o quadril dela é menor, por isso é mais fácil dela saltar. Em alguns momentos sim, no início do jogo, eu tive uma sensação que ela segura um pouco, foi mais na habilidade, tentou vir com menos força, mas na decisão ela vem para decidir mesmo. Ela vem forte. Em alguns momentos faz diferença. ${ }^{9}$

Tandara Caixeta é uma atacante de ponta de rede (oposta, mais especificamente), é campeã olímpica pelo Brasil nos Jogos de Londres (2012) e defendeu a equipe do SESC Rio de Janeiro na última edição da Superliga. Em suas

\footnotetext{
7 BOTTA, Emílio. Campeã olímpica Thaísa defende amiga Tifanny. Disponível em: https://globoesporte.globo.com/ sp/tem-esporte/volei/noticia/bicampea-olimpica-thaisa-defende-amiga-tifanny-tem-que-ver-o-lado-humano.ghtml. Acesso em: 06 ago. 2020.

8 PAIS, Sérgio. Bi olimpica, Fabi não vê anormalidade em Tifanny. Disponível em: https://globoesporte.globo.com/sp/ tem-esporte/volei/noticia/bi-olimpica-fabi-nao-ve-anormalidade-em-tifanny-forca-do-nivel-da-tandara.ghtml. Acesso em: 06 ago. 2020.

9 COSTA, Guilherme. "Respeito, mas não concordo com ela no feminino", diz Tandara sobre Tifanny. Disponível em: https://globoesporte.globo.com/volei/noticia/respeito-mas-nao-concordo-com-ela-no-feminino-diz-tandara-sobretifanny.ghtml. Acesso em: 07 ago. 2020.
} 
primeiras entrevistas concedidas sobre o tema, Tandara foi cautelosa e disse não possuir estofo para opinar sobre o assunto, porém, em suas declarações posteriores, posicionou-se contrária à participação de mulheres trans no esporte feminino, coadunando com o discurso de Ana Paula e trazendo como arcabouço o discurso fisiológico das diferenças entre os corpos de homens e mulheres cis. Para a atleta, tanto Tifanny quanto as demais atletas trans apresentam vantagens biofisiológicos em função da memória musculoesquelética desenvolvida antes da transição.

Sheilla Tavares de Castro Blassioli: É realmente muito polêmico esse assunto. Antes do Natal, eu dei uma entrevista sobre isso e, na época, eu estava meio por fora. Conversei com a Fabiana sobre isso, e ela disse: "Espera para ver ela jogar". Depois que vi uma entrevista do médico Paulo Zogaib, mudei de opinião. Hoje sou contra. Ela tem a força de um homem. Eu a Fabiana estávamos falando sobre isso outro dia. Imagina se isso vira uma onda, por que não precisa mais de cirurgia. Imagina se todos os gays e viados decidem jogar a Superliga? Vai ficar complicado, porque não temos como competir com eles.

[...] Gente, estou vendo como suscitei um ódio incrível sobre o caso da Tiffany. Eu dei uma entrevista logo depois do Natal dizendo que eu era a favor da participação dela na Superliga feminina, mas que não podia opinar com profundidade porque não entendia do assunto, sobretudo a respeito de hormônios e da formação corporal. Depois, após ler a opinião de médicos, vi outro lado da história, que está na vantagem física que a Tiffany leva sobre as demais jogadoras, mesmo hoje controlando os hormônios. Então, me reposicionei. Disse que sou contra. Claro que precisamos buscar uma solução pra situação. Na entrevista, a Renata e a Roberta falaram em cotas, eu concordei que talvez seja a solução para não excluir ninguém. O esporte é sim um ambiente de inclusão social e vai continuar sendo. A Tiffany é pioneira nisso e ainda terão muitas discussões sobre o assunto. E este é meu posicionamento. Respeito opiniões contrárias e espero respeito tb [sic]. ${ }^{10}$

Sheilla Castro atua como oposta de rede na equipe do Itambé/Minas Tênis Clube e é bicampeã olímpica pelo Brasil nos Jogos de Pequim (2008) e Londres (2012). Em um primeiro momento, Sheilla foi favorável à inclusão de mulheres trans, e Tifanny, no esporte feminino, porém após conversar com médicos esportivos, mudou sua opinião com base nos mesmos preceitos já elencados por Tandara. Para a atleta, também, a flexibilização das recomendações dos órgãos regulamentadores, se não conduzida de forma cautelosa, pode abrir margem para a inserção de homens homossexuais não transgenitalizados (isto é, sem realização da cirurgia de redesignação sexual) nas competições femininas, o que seria um atentado ao direito de competição no espaço das mulheres cis.

Danielle Lins: Eu não gosto de entrar em polêmica, eu ando de acordo com o que está na regra, e se a regra permite, eu apoio. Agora a Tiffany [sic] é minha parceira, minha companheira de equipe, e eu vou dar muita bola pra ela. Jogo com ela e quero ser campeã com ela. ${ }^{11}$

Dani Lins joga na posição de levantadora, possui o ouro olímpico dos Jogos de Londres (2012) e desde 2019 atua pelo SESI Vôlei Bauru juntamente de Tifanny. Para a atleta, a atuação de Tifanny está respaldada pelos regulamentos vigentes, justificativa que ela aciona para expor seu depoimento isento de posição. Para ela, é

10 SHEILLA gera mal-estar... Disponível em: https://globoesporte.globo.com/volei/noticia/sheilla-gera-mal-estarapos-comentario-sobre-tiffany-imagina-se-vira-onda.ghtml. Acesso em: 07 ago. 2020.

11 PAIS, Sérgio. Longe das polêmicas, Dani Lins chega ao Sesi-Bauru com planos de voltar à seleção. Disponível em: $\quad$ https://globoesporte.globo.com/sp/tem-esporte/volei/noticia/longe-das-polemicas-dani-lins-chega-ao-sesibauru-com-planos-de-voltar-a-selecao.ghtml. Acesso em: 08 ago. 2020. 
justa a participação de Tifanny entre as mulheres uma vez que esta segue todas as recomendações a ela imposta para que seja elegível para atuar.

Aline Cristina Santos da Silva: O ataque dela é forte sim, é pesado, mas a Tandara também ataca pesado, ataca forte. Ela também erra, também larga. Ela se sobressai? Sobressai sim. Mas eu não achei tudo isso que todo mundo fala. Ela recebe noventa bolas por jogo, é normal ela fazer trinta pontos. Vamos ver os confrontos contra os times grandes, contra o Rio, contra o Praia. Porque daqui a pouco esses times vão começar também a parar o ataque dela. ${ }^{12}$

Maria Luísa Silva Ramos de Oliveira: Eu realmente acho que ela é uma atacante muito forte que se sobressai em alguns momentos. Não sei se tem a ver porque foi homem ou não foi, não sei. Até nem gosto de falar muito porque quem liberou é que tem que segurar esse rojão aí. ${ }^{13}$

Colegas de equipe, Aline Silva e Maria Luísa defendiam a equipe do Brasília Vôlei quando concederam entrevistas opinando sobre a participação de Tifanny na Superliga feminina. Para Aline, a atleta é diferenciada em quadra, possuindo força acima da média para as mulheres cis, porém não o suficiente para justificar tamanha repercussão de seu caso. Atentando para desacertos, demais jogadas e quantidade de bolas por Tifanny recebidas, Aline acredita que o caso esteja sendo supervalorizado em função das polêmicas que giram sobre a temática. Já Maria Luísa não se sente muito confortável para tratar sobre o assunto, talvez em função da complexidade do mesmo, sustentando uma ideia inicial de que Tifanny leva, em alguns momentos, vantagem física por se sobressair em quadra, o que poderia estar relacionado ao seu histórico corporal de antes da transição.

\subsection{O DISCURSO DOS TREINADORES}

Paulo de Tarso: O que a gente quer é que seja analisado porque existe uma diferença. Só isso. Ninguém é contra, ninguém é transfóbico, ninguém é homofóbico, ninguém é absolutamente nada disso. Pelo contrário, eu sou solidário a todo o trabalho que ela teve pra chegar ao lugar que ela conquistou. ${ }^{14}$

Na época, o treinador Paulo de Tarso polemizou ao cobrar dos dirigentes organizacionais que reorganizassem seus critérios para permitir a elegibilidade de Tifanny na Superliga feminina. O fato rendeu inúmeros comentários e o adjetivo de "transfóbico" para o técnico que, ao conceder novas entrevistas, defendeu-se explicando que se solidariza com o percurso histórico de Tifanny, porém que a atleta apresentava diferenças significativas em termos fisiológicos quando comparada às mulheres cis.

Paulo Coco: A minha opinião é que os órgãos que regulamentam o esporte, no caso o Comitê Olímpico Internacional e a Federação Internacional, acredito que devam rever, discutir mais essa normatização. Pelo que eu tenho acompanhado, informações de especialistas na área médica esportiva, fisiologistas, não é simplesmente o fato do controle hormonal, em cima de taxas de testosterona, que colocaria um transexual em condições de igualdade de mulheres. ${ }^{15}$

12-13 ENVOLVIDA em polêmica... Disponível em: https://globoesporte.globo.com/programas/esporte-espetacular/ noticia/envolvida-em-polemica-tiffany-desabafa-forca-de-uma-mulher.ghtml. Acesso em: 07 ago. 2020.

14-15 ENVOLVIDA em polêmica... Disponível em: https://globoesporte.globo.com/programas/esporte-espetacular/ noticia/envolvida-em-polemica-tiffany-desabafa-forca-de-uma-mulher.ghtml. Acesso em: 07 ago. 2020. 
Paulo Coco é treinador da equipe Dentil Praia Clube e também assistente técnico da seleção feminina. No início, preferia não se pronunciar sobre o assunto, o que veio a ocorrer posteriormente ao expor sua opinião, de maneira cautelosa, defendendo que as recomendações deveriam ser revistas, já que o rendimento de atletas não é definido única e exclusivamente pelas taxas hormonais do corpo. Pelo que sugere, preliminarmente, novas recomendações são necessárias.

\begin{abstract}
José Roberto Guimarães: Eu acho que se ela foi elegível pelo Comitê Olímpico Internacional, pela Federação Internacional de Vôlei, pela Confederação Brasileira, ela é elegível para jogar em qualquer lugar, até na seleção brasileira. Se ela tiver nível, ela pode jogar sim na seleção. ${ }^{16}$

A minha opinião é a mesma que dei quatro meses atrás. Se ela é elegível para o COI, FIVB e pela CBV, ela é elegível para qualquer coisa. Não cabe a nós ficarmos discutindo isso. ${ }^{17}$
\end{abstract}

Zé Roberto, como é mais conhecido, é treinador da equipe São Paulo/ Barueri e também da seleção feminina. Possui prestígio e reconhecimento notórios, principalmente por ter conquistado o primeiro ouro olímpico com a seleção masculina de voleibol nos Jogos de Barcelona (1992) e o bicampeonato olímpico com a seleção feminina nos Jogos de Pequim (2008) e Londres (2012). Quando Tifanny surgiu no cenário nacional, houve muita especulação midiática sobre uma possível convocação da mesma para representar a seleção em competições internacionais. Sobre o assunto, o técnico sempre manteve a mesma opinião: se Tifanny está apta para jogar no feminino de acordo com as normas já estabelecidas e apresentar rendimento satisfatório, poderá vir a compor o quadro de convocadas para representar o país.

Bernardo Rocha de Rezende: Não é questão técnica, de um técnico que tem história ou não, acho que é uma questão dos médicos. Questão de avaliar se ela tem uma vantagem ou não. Não sou a pessoa mais indicada para dizer. Eu acho que a conversa e a análise devem ser profundas, não deve ser uma análise rasa. Sem qualquer tipo de preconceito. [...] No esporte profissional você não pode se beneficiar por doping, seja natural ou artificial. Se os cientistas do assunto disseram que ela não tem vantagem, perfeito. Se há alguma vantagem, é de se repensar. Quero apenas que haja um estudo sério, uma conversa profunda e séria sobre isso, sem polarizações ou discussões sem sentido, sempre com respeito. ${ }^{18}$

Bernardinho, como é popularmente conhecido, é o treinador da equipe feminina do hoje SESC/Flamengo, sendo o técnico mais vitorioso da competição nacional de voleibol. Foi, de 2001 a 2016, técnico da seleção masculina de voleibol brasileira de quadra, tendo conquistado dois ouros olímpicos nos Jogos de Atenas (2004) e Rio (2016) e duas pratas nos Jogos de Pequim (2008) e Londres (2012). Bernardinho sempre foi cauteloso sobre a temática e se ancora nas decisões de médicos e demais profissionais da área para formar sua opinião de que não lhe compete discutir sobre o assunto, mas sim prezar pela confiabilidade, seriedade e serenidade de se abordar a temática (tanto no campo epistemológico, quanto científico e empírico).

\footnotetext{
16 OLIVEIRA, Carol; GUERRA, Marcos. Leva vantagem? Consultora do COI não acredita em reviravolta do caso Tifanny. Disponível em: https://globoesporte.globo.com/volei/noticia/leva-vantagem-consultora-do-coi-nao-acreditaem-reviravolta-do-caso-tifanny.ghtml. Acesso em: 07 ago. 2020.

17 BOTTA, Emilio. Zé Roberto se irrita com perguntas sobre Tifanny na seleção: "Não cabe discutir". Disponível em: https://globoesporte.globo.com/sp/tem-esporte/volei/noticia/ze-roberto-se-irrita-com-perguntas-sobre-tifannyna-selecao-nao-cabe-discutir.ghtml. Acesso em: 07 ago. 2020.

18 PAIS, Sérgio. Bernardinho defende diálogo no caso Tifanny. Disponível em: https://globoesporte.globo.com/sp/ tem-esporte/volei/noticia/bernardinho-defende-dialogo-no-caso-tifanny-avaliar-se-ela-tem-vantagem.ghtml. Acesso em: 07 ago. 2020.
} 


\subsection{ANALISANDO O(S) DISCURSO(S)}

Após registrar e analisar nossos dados, organizamos o Quadro 1, que sintetiza o posicionamento de nosso grupo amostral:

Quadro 1 - Especificação dos depoimentos*

\begin{tabular}{|c|c|c|c|c|}
\hline $\begin{array}{c}\text { Data da } \\
\text { entrevista }\end{array}$ & Depoente & Cargo & Equipe & Posição \\
\hline $19 / 12 / 2017$ & Ana Paula Henkel & Ex-atleta & - & Contrária \\
\hline $24 / 12 / 2018$ & Virna Dias & Ex-atleta & - & $\begin{array}{c}\text { Cautelosamente } \\
\text { favorável }\end{array}$ \\
\hline $20 / 02 / 2018$ & Thaísa Daher de Menezes & Atleta & Hinode Barueri & $\begin{array}{c}\text { Cautelosamente } \\
\text { favorável }\end{array}$ \\
\hline $08 / 02 / 2018$ & Fabiana Alvim de Oliveira & Atleta & $\begin{array}{l}\text { SESC Rio de } \\
\text { Janeiro }\end{array}$ & $\begin{array}{c}\text { Cautelosamente } \\
\text { favorável }\end{array}$ \\
\hline 02/02/2018 & Tandara Alves Caixeta & Atleta & Osasco Nestlé & Contrária \\
\hline $20 / 01 / 2018$ & $\begin{array}{c}\text { Sheilla Tavares de Castro } \\
\text { Blassioli }\end{array}$ & Atleta & Sem clube & Contrária \\
\hline 07/05/2019 & Danielle Lins & Atleta & $\begin{array}{l}\text { SESI Vôlei } \\
\text { Bauru }\end{array}$ & $\begin{array}{c}\text { Cautelosamente } \\
\text { neutra }\end{array}$ \\
\hline $14 / 01 / 2018$ & Aline Cristina Santos da Silva & Atleta & Brasília Vôlei & $\begin{array}{c}\text { Cautelosamente } \\
\text { neutra }\end{array}$ \\
\hline $14 / 01 / 2018$ & $\begin{array}{c}\text { Maria Luísa Silva Ramos de } \\
\text { Oliveira }\end{array}$ & Atleta & Brasília Vôlei & $\begin{array}{c}\text { Cautelosamente } \\
\text { contrária }\end{array}$ \\
\hline $14 / 01 / 2018$ & Paulo de Tarso & Treinador & Pinheiros Vôlei & $\begin{array}{c}\text { Cautelosamente } \\
\text { contrário }\end{array}$ \\
\hline $14 / 01 / 2018$ & Paulo Coco & Treinador & $\begin{array}{l}\text { Dentil Praia } \\
\text { Clube }\end{array}$ & $\begin{array}{c}\text { Cautelosamente } \\
\text { contrário }\end{array}$ \\
\hline $\begin{array}{l}01 / 02 / 2018 \\
17 / 02 / 2018\end{array}$ & José Roberto Guimarães & Treinador & Hinode Barueri & $\begin{array}{c}\text { Cautelosamente } \\
\text { neutro }\end{array}$ \\
\hline $08 / 02 / 2018$ & Bernardo Rocha de Rezende & Treinador & $\begin{array}{l}\text { SESC Rio de } \\
\text { Janeiro }\end{array}$ & $\begin{array}{c}\text { Cautelosamente } \\
\text { neutro }\end{array}$ \\
\hline
\end{tabular}

Fonte: os autores

* Todos os dados fornecidos são com base no momento das entrevistas

Conforme apontam Gill (2002) e Orlandi (2011), ao trabalharmos com a técnica de análise de discurso, é importante estar atento para as inúmeras formas de se investigar os enunciados linguísticos, extrapolando searas significativas, simbólicas e semânticas. A construção e veiculação de um discurso se faz a partir de outros discursos já pré-estabelecidos, que vão se perpetuando pela constante enunciação de seus sujeitos, modificando-se e reestruturando em novos e mutáveis processos de poder e saber.

Neste sentido, quando nos debruçamos a estudar sobre a opinião de atletas e treinadores de voleibol sobre a participação de mulheres trans no naipe feminino, é primordial entender que, antes de tudo, a formulação de seus discursos partem 
de relações contextuais e sócio-históricas dos/as depoentes a partir de valores intrínsecos às suas próprias identidades e experiências.

Dado isto, resgatamos a matriz social cistêmica para problematizar de que forma ela está presente de forma importante para alicerçar a opinião de nosso grupo investigado. Vergueiro (2014) afirma que o regime cis-sexista enfatiza, neste caráter sistêmico e estrutural, processos institucionalizados de inferiorização das pessoas trans, incluindo a transfobia (que, em suma, resume-se a todo ato discriminatório, ofensivo e/ou de não reconhecimento das identificações trans).

Esse regime, estendido ao Esporte, ignora que os corpos possam se apresentar diferentes da identificação cis. Nas opiniões de Ana Paula, Tandara e Sheilla, que sustentaram seus pontos de vista abertamente contrários à participação das mulheres trans no esporte feminino, percebemos que se assentam na perspectiva do discurso biomédico para legitimar a separação competitiva entre cis e trans, o que Maria Luísa, Paulo de Tarso, Paulo Coco e Bernardinho também o fazem, porém de maneira mais branda e cautelosa.

Aqui, desponta como sustentação argumentativa a instância que, dentro do cistema-mundo, possui o poder de determinar os corpos normais nas sociedades contemporâneas, que é o Biopoder Médico (VERGUEIRO, 2014). A partir de interpretações decoloniais, Vergueiro $(2014 ; 2015)$ problematiza como o sistema médico, que vem da racionalidade eurocêntrica de catalogação das anormalidades, tenta construir justificativas científicas, objetivas e racionais por meio de instrumentos e dispositivos sociais de poder. É possível, então, compreender porque o discurso biomédico é acionado como respaldo legítimo da posição dos/as entrevistados. Para além de estabelecer diferenças corporais ainda pouco aprofundadas (no caso, o rendimento de corpos trans que fazem tratamento com hormônios cruzados), também se vale dos já processos cistêmicos cristalizados pelas instâncias sociais, dentre elas o Esporte, o que mantém a rigidez das normatizações cisheteronormativas que há muito rodeiam e vigiam o fenômeno esportivo na atualidade (JARDIM, 2018).

Outro aspecto pertinente que contribui para moldar a opinião das atletas que se posicionaram contrárias é o receio de que as competições femininas possam ser "invadidas" pelas mulheres trans e/ou atletas homens homossexuais que não realizaram cirurgia de transgenitalização. Embora proteger o direito de participação de mulheres cis no Esporte seja louvável, já que historicamente este público teve de vencer inúmeros percalços sociais e legais para que pudesse se consolidar neste espaço (KNIJNIK, 2003; GOELLNER, 2016), esse temor parece ser pouco provável de se materializar.

Machado (2019) explicita as dificuldades que as pessoas trans têm de enfrentar para se inserir no Esporte se comparadas às pessoas cis: além de comporem um baixo número da população mundial, falta-lhes incentivos para inserção e manutenção no Esporte, bem como não se pode admitir que desta pequena parcela, muitas queiram tornar-se atletas de alto rendimento. Também, a autora traz um panorama de como as variáveis genéticas e fisiológicas, em conjunto com o meio, se constroem e se alteram, legitimando sentidos de pertença, (des)vantagens e condições desiguais entre todo tipo de corpo que se aventura às práticas esportivas. 
O desconhecimento das identificações e realidades de gênero não cistêmicas contribui inclusive para o pensamento de que homens homossexuais prefeririam competir pelo naipe feminino em função de sua orientação sexual. Neste pensamento, a ideia da preferência sociossexual se borra com a de identificação de gênero, e permite uma interpretação errônea do que dispõe o COI em suas regulamentações. O órgão diz, em seu documento, que para competir entre as mulheres cis, a atleta trans deve, obrigatoriamente, atender a quatro requisitos: 1- declarar-se no gênero mulher, invariavelmente para fins esportivos, por no mínimo quatro anos; 2- apresentar taxas de testosterona no sangue igual ou inferior a $10 \mathrm{nmol} / \mathrm{L}$ nos 12 primeiros meses anteriores à primeira competição, bem como após; 3- manter essa taxa controlada e monitorada mensalmente; 4- em caso de inobservância, a atleta é suspensa por 12 meses (IOC, 2015). Portanto, o cenário de homens homossexuais competindo com mulheres cis ilustra insciência e incompreensão das postulações do COI, já que eles não cumprem os requisitos e, antes disso, identificam-se como homens, não como mulheres.

Contudo, é possível perceber certo afrouxamento das teias cistêmicas quando vemos posicionamento mais flexíveis quanto à participação de Tifanny no voleibol e, em consequência, de mulheres trans, como se pode notar nas falas de Virna, Thaísa, Fabi, Dani Lins e Zé Roberto. Nestas, a absorção da expressividade trans já é possível se, dentro do regimento estabelecido pelas entidades que regem as competições, a atleta esteja dentro dos parâmetros para ela estabelecido. À luz de Pontes e Silva (2018), essa experenciação pode ser compreendida, entretanto, como complexa e ambígua, já que por um lado mantém a (im)posição e exigência normativas do/no registro cisgênero, por outro, deflagra uma estratégia de segurança e sobrevivência diante às situações que derivam de sua(s) própria(s) existência.

A estratégia de cautela presente na maioria dos discursos analisados também é outro elemento fundamental para nortear o posicionamento dos/as sujeitos/as-alvo da pesquisa, principalmente os treinadores, já que ao mesmo tempo que admitem possíveis parcialidades, também dialogam com variados desfechos sobre a temática, os quais à ciência vem se debruçando atualmente para desvendar (MACHADO, 2019). Como aponta a autora, não há consenso científico ainda sobre a elegibilidade e legitimidade de mulheres trans em competições femininas, uma vez que na esfera esportiva, uma complexidade de variáveis interfere no resultado, mérito e rendimento de atletas profissionais que não apenas as taxas hormonais (e, mais especificamente, da testosterona, conforme sinaliza o $\mathrm{COI}$ ).

Neste universo polissêmico dos discursos, também é importante observar que o histórico pessoal dos/as depoentes contribui para a formação e disseminação de valores simbólicos à temática. Tivemos no grupo discursivo nomes de atletas e treinadores que são reconhecidos internacionalmente pela sua história e dedicação ao voleibol brasileiro, colecionando títulos expressivos que os/as condecoram como líderes e/ou ídolos. Essa peculiaridade, todavia, só foi destrinchada nos dizeres do treinador Bernardinho, que distancia sua história no voleibol brasileiro do estofo científico-técnico que ele não detém para dizer com certeza se a atuação de mulheres trans junto às cis é plenamente viável e/ou legítima. 
Mesmo com posições contrárias, outras mais favoráveis e, ainda, outras mais cuidadosamente tecidas pedindo por mais estudos, é de se enfatizar que em nenhum dos discursos pudemos vislumbrar, de fato, propósitos reflexivos com base em elementos decoloniais e/ou pós-coloniais que problematizassem, ou rompessem, o cistema heteronormativo vigente no Esporte. Ou seja, não se pensou em nenhum momento em propor uma nova categorização para as competições esportivas, mas sim em continuar fixando a divisão cistêmica esportiva em masculino e feminino, ambos opostos e intransigentes. Em meio a este universo, identificamos que a biopolítica médica cis está enraizada no pensamento de atletas e treinadores, encontrando assim fertilidade suficiente para que possa continuar a subsidiar as práticas esportivas enquanto espaço de constituição, regulação e produção de corpos cisnormativos.

Cabe sinalizar aqui que, com o surgimento do esporte moderno a partir do século XVIII, os meios biotecnológicos para se organizar esse fenômeno pautaramse nos discursos biomédicos sobre os sexos porque eram os artifícios dos quais se podiam lançar uso nos séculos passados, ainda que identifiquemos forte imposição das normas cis sobre esses corpos e seus rendimentos. Com o avanço da medicina e biomedicina, sobretudo na área esportiva, que hoje já transformam corpos e ilustram uma nova realidade, de pessoas modificáveis, ciborgues, bio-corpos e/ou tecnocorpos (PRECIADO, 2014), o fenômeno esportivo parece ter parado nos tempos de sua criação ao persistir em continuar moldando performances a partir de masculino e feminino. Fica aqui a reflexão: um problema do Esporte a ser repensado, ou, de fato, mais uma opressão mascarada, porém gritante, do cistema-mundo para continuar legitimando seu poder de normatização dos corpos à luz da biopolítica médica?

\section{CONSIDERAÇÕES FINAIS}

Este estudo teve por objetivo averiguar a opinião de atletas e treinadores cis de voleibol sobre a participação de mulheres trans no naipe feminino da modalidade a partir do caso de Tifanny Abreu. Percebemos que o discurso das atletas e treinadores foi, em maioria, contrário a essa inserção e atuação, com base em preceitos biomédicos e fisiológicos cisheteronormativos. Entretanto, registraram-se manifestações mais cautelosas sobre o assunto, legitimando a participação de acordo com as recomendações das federações que regem as modalidades esportivas.

$\mathrm{O}$ dado resultante mais significativo sugere que, embora vislumbremos oscilações, é impossível desvencilhar a construção do discurso do grupo pesquisado do regime de cistematização aplicado ao universo esportivo da atualidade. Para a construção de seus depoimentos, não houve como desviar de contextos, historicidade e demais eventos socioculturais que permeiam a história de vida das atletas e treinadores, bem como da própria jogadora Tifanny Abreu.

Por fim, cabe frisar que este trabalho teve como propósito registrar a opinião de profissionais diretamente relacionados à temática em questão, já que, juntos/ as, podem contribuir para promover mudanças significativas aos expectadores, competições e demais agentes envolvidos no universo do Esporte profissional. 


\section{REFERÊNCIAS}

COUTO JUNIOR, Dilton Ribeiro et al. Jovens em estado de alerta no Facebook: diálogos tecidos em/na rede como estratégia de (re-)existência à regulação das vidas precarizadas. Práxis Educativa, v. 14, n. 3, p. 1210-1229, set./dez. 2019.

GILL, Rosalind. Análise de Discurso. In: BAUER, Martin W.; GASKELL, George. Pesquisa qualitativa com texto, imagem e som: um manual prático. 3. ed. Petrópolis: Vozes, 2002. p. 244-270.

GOELLNER, Silvana Vilodre. Jogos Olímpicos: a generificação de corpos performantes. Revista USP, n. 108, p. 29-38, jan./mar. 2016.

GRESPAN, Carla Lisboa; GOELLNER, Silvana Vilodre. Fallon Fox: um corpo queer no octógono. Movimento, v. 20, n. 4, p. 1265-1282, out./dez. 2014.

IOC - INTERNATIONAL OLYMPIC COMMITTEE. IOC Consensus Meeting on Sex Reassigment and Hyperandrogenism. 2015. Disponível em: https://stillmed.olympic.org/ Documents/Commissions_PDFfiles/Medical_commission/2015-11_ioc_consensus_meeting on_sex_reassignment_and_hyperandrogenism-en.pdf. Acesso em 09 abr. 2020.

JARDIM, Juliana Gomes. "It's time"! MMA feminino, mercado da beleza e CIS heteronormatividade: uma etnografia multissituada com lutadoras brasileiras. 2018. 225 f. Tese (Doutorado em Ciências Sociais) - Faculdade de Filosofia e Ciências, Universidade Estadual Paulista Júlio de Mesquita Filho, UNESP, Marília,SP, 2018.

JESUS, Jaqueline Gomes de. Orientações sobre identidade de gênero: conceitos e termos. Brasília: [s.n.], 2012.

KNIJNIK, Jorge Dorfman. A mulher brasileira e o esporte: seu corpo, sua história. São Paulo: Editora Mackenzie, 2003.

MACHADO, Anna Cristina Alvares Ribeiro. Alguns apontamentos sobre a diversidade de gênero nos esportes. RECITAL - Revista de Educação, Ciência e Tecnologia de Almenara, v. 1, n. 2, p. 37-60, set./dez. 2019.

ORLANDI, Eni Pulcinelli. A linguagem e seu funcionamento: as formas do discurso. 6. ed. Campinas: Pontes, 2011.

PONTES, Júlia Clara de; SILVA, Cristiane Gonçalves da. Cisnormatividade e passabilidade: deslocamentos e diferenças nas narrativas de pessoas trans. Periódicus: Revista de estudos indisciplinares em gêneros e sexualidades, v. 1, n. 8, p. 396-417, nov. 2017/abr. 2018.

PRECIADO, Paul Beatriz. Manifesto Contrassexual: práticas subversivas de identidade sexual. São Paulo: n-1 edições, 2014.

VERGUEIRO, Viviane (Simakawa). Colonialidade e cis-normatividade: entrevista com Viviane Vergueiro, por Boris Ramírez Guzmán. Revista Iberoamérica Social, v. 3, p. 15-21, 2014. Disponível em: https://iberoamericasocial.com/wp-content/uploads/2015/01/ Ram\%C3\%ADrez-B.-2014.-Colonialidad-e-cis-normatividade.-Entrevista-con-VivianeVergueiro..pdf . Acesso em 8 abr. 2020.

VERGUEIRO, Viviane (Simakawa). Por inflexões decoloniais de corpos e identidades de gênero inconformes: uma análise autoetnográfica da cisgeneridade como normatividade. 2015. 243f. Dissertação (Mestrado em Cultura e Sociedade). Instituto de Humanidades, Artes e Ciências Professor Milton Santos, Universidade Federal da Bahia, Salvador/BA, 2015. 
Abstract: We aim to investigate the opinion of athletes and volleyball coaches about the participation of trans women in female volleyball from the case of athlete Tifanny Abreu. To guide this objective, we ask: what is the position of those involved regarding this participation and how do they structure and present their point of view? We collected 38 reports from the sports website globoesporte.com that dealt with trans participation in volleyball from the case of Tifanny. Of this total, only 11 covers had the testimony of 9 athletes and 4 coaches, who were analyzed using the speech analysis technique. As a result, we realized that the group studied was, in the majority, opposed to this insertion and performance based on cisheteronormative biomedical and physiological norms. However, there were more cautious demonstrations on the subject, legitimizing participation in accordance with the recommendations of the confederations and federations that govern sports.

Keywords: Sports. Volleyball. Transgender persons.

Resumen: Apuntamos investigar la opinión de atletas y entrenadores de voleibol sobre la participación de mujeres trans en el voleibol femenino a partir del caso de la atleta Tifanny Abreu. Para guiar este objetivo, preguntamos: ¿cuál es la posición de los/ as involucrados/as con respecto a esta participación y cómo estructuran y presentan su punto de vista? Recopilamos 38 informes del sitio de deportes globoesporte.com que trataban sobre la participación trans en voleibol a partir del caso de Tifanny. Solo 11 reportajes tenían el testimonio de 9 atletas y 4 entrenadores, quienes fueron analizados utilizando la técnica de análisis del habla. Como resultado, destacamos que el grupo estudiado se oponía, en su mayoría, a esta inserción y rendimiento basados en normas biomédicas y fisiológicas cisheteronormativas. Sin embargo, hubo manifestaciones más cautelosas sobre el tema, legitimando la participación de acuerdo con las recomendaciones de las confederaciones y federaciones que gobiernan los deportes.

Palabras clave: Deportes. Voleibol. Personas transgénero. 


\section{LICENÇA DE USO}

Este é um artigo publicado em acesso aberto (Open Access) sob a licença Creative Commons Atribuição 4.0 Internacional (CC BY 4.0), que permite uso, distribuição e reprodução em qualquer meio, desde que o trabalho original seja corretamente citado. Mais informações em: http://creativecommons.org/licenses/by/4.0

\section{CONFLITO DE INTERESSES}

Os autores declararam que não há conflito de interesses neste trabalho.

\section{CONTRIBUIÇÕES DE AUTORAIS}

Rafael Marques Garcia: Elaboração do trabalho; Discussão dos principais pontos a serem abordados; Dissertação conforme aporte bibliográfico e referências; Revisão metodológica; Aprimoramento das discussões; Revisão linguística; Formatação conforme as normas da revista e submissão na plataforma online

Erik Giuseppe Barbosa Pereira: Orientação.

\section{FINANCIAMENTO}

O presente trabalho foi realizado sem qualquer apoio financeiro.

\section{COMO CITAR}

GARCIA, Rafael Marques; PEREIRA, Erik Giuseppe Barbosa. A opinião de atletas e treinadores de voleibol sobre a participação de mulheres trans. Movimento, v. 26, p. e 26068, 2020. Disponível em: https://seer.ufrgs.br/Movimento/article/ view/101993. Acesso em: 30 set. 2020. DOI: https://doi.org/10.22456/1982$\underline{8918.101993}$

\section{RESPONSABILIBADE EDITORIAL}

Alex Branco Fraga*, Elisandro Schultz Wittizorecki ${ }^{*}$, Humberto Cesaro**, Ivone Job* $^{*}$ Mauro Myskiw*, Raquel da Silveira*

*Universidade Federal do Rio Grande do Sul, Escola de Educação Física, Fisioterapia e Dança, Porto Alegre, RS, Brasil

**Instituto Federal Catarinense (IFC). Departamento de Desenvolvimento Educacional, Luzerna/SC, Brasil 